\title{
The relationship between hormone replacement therapy and periodontal disease in postmenopausal women: a cross-sectional study the Korea National Health and Nutrition Examination Survey from 2007 to 2012
}

Yunhee Lee ${ }^{1}$ (D) Inah Kim ${ }^{2 *}$, Jaechul Song ${ }^{2}$ (D) Kyung-Gyun Hwang ${ }^{3}$ (D) Boyoul Choi ${ }^{4}$ (D) and Seung-Sik Hwang ${ }^{5}$ (D)

\begin{abstract}
Background: The purpose of this study was to investigate the relationship between hormone replacement therapy (HRT) and periodontal disease in postmenopausal women using data from the 4th and 5th Korea National Health and Nutrition Examination Survey (KNHANES).

Methods: The study included data from 5,482 postmenopausal women aged 45-74 years in the 2007-2012 KNHANES. The use of female HRT for at least one month was reclassified as HRT+/HRT-. The Community Periodontal Index of Treatment Needs (CPITN) was used to assess periodontal status. Propensity score matching (PSM) was used to control selection bias, and factors affecting education, family income, and age of menopause were used as covariates in PSM. A chi-square test was used to confirm the bivariate relationship between the variables. Binary logistic regression analysis was used to adjust for confounders (age, education, family income, body mass index, age of menopause, alcohol, smoking, dental clinic visits in the past one year, use of oral care products and frequency of tooth brushing per day).

Results: After adjusting for all covariates, HRT was associated with periodontal disease (OR: 0.79; 95\% Cl: 0.66-0.94). In particular, the relationship between HRT and periodontal disease was more evident in those with menopause under 45 years of age disease (OR: 0.55; 95\% Cl: 0.35-0.87).
\end{abstract}

Conclusions: The results of this study supported that it is important that hormone therapy be actively considered in the policy towards postmenopausal women. Especially, health programs such as hormone replacement therapy, non-smoking, and use of oral care products are needed for women who undergo premature menopause.

Keywords: Hormone replacement therapy, Menopause, Periodontal disease

\footnotetext{
* Correspondence: inahkim@hanyang.ac.kr

${ }^{2}$ Department of Occupational and Environment Medicine, College of

Medicine, Hanyang University, 222 wangsimni-ro, Seongdong-gu, Seoul,

Republic of Korea

Full list of author information is available at the end of the article
}

(c) The Author(s). 2019 Open Access This article is distributed under the terms of the Creative Commons Attribution 4.0 International License (http://creativecommons.org/licenses/by/4.0/), which permits unrestricted use, distribution, and reproduction in any medium, provided you give appropriate credit to the original author(s) and the source, provide a link to the Creative Commons license, and indicate if changes were made. The Creative Commons Public Domain Dedication waiver (http://creativecommons.org/publicdomain/zero/1.0/) applies to the data made available in this article, unless otherwise stated. 


\section{Background}

The World Health Organization (WHO) defines natural menopause as 12 months of consecutive amenorrhea without an apparent cause, such as pregnancy or lactation [1]. While menopausal age varies between individuals and races, the average menopausal age for countries has been reported to be around 50 years [2]. The average menopausal age of women in Korea is 49.7 years. Considering that the life expectancy of Korean women was 85.2 years in 2015 [3], Korean women are expected to spend over one-third of their life, or approximately 35.5 years, in the menopausal state [4]. Menopause is a phenomenon that occurs naturally with aging, but postmenopausal women face increased risk of various diseases, including osteoporosis and cardiovascular diseases [5].

Postmenopausal women experience a rapid decrease in bone mineral density (BMD) due to hormone (estrogen) deficiency [6]. Meanwhile, Osteoporosis and periodontal diseases are indicative of excessive bone resorption, as both diseases have host-dependent, multifactorial causes and are regulated by local and systemic cytokines, such as IL-1 and 6, and various hormones [7]. When the periodontal status of menopausal women with osteoporosis was investigated, more severe periodontal pocket depth and attachment loss was found compared to those in the same age group who did not have osteoporosis [8]. In particular, menopause-related hormonal changes are known to affect the oral environment, due to changes in sex hormones, such as estrogen, progesterone, and testosterone, which have an impact on the secretion of proinflammatory cytokines that are involved in bone resorption [9]. Moreover, estrogen receptors in the oral mucosa react sensitively to changes in hormone levels, which leads to increased inflammation in the periodontal tissues [10].

The need for hormone replacement therapy (HRT) was presented as a means to alleviate menopausal symptoms so that a woman's quality of life can be improved during menopause [11]. HRT plays an important role in preventing osteoporosis by reducing postmenopausal bone mass loss [12]. Menopausal women who received estrogen therapy showed a significantly increased density in their lumbar spine and femur, as compared to the control group; while, similar results were found in the alveolar bone as well [13]. Postmenopausal HRT is widely recognized to prevent osteoporosis and improve menopause-related diseases [14]. Since periodontal diseases are also affected by the state of the alveolar bone, various studies have attempted to demonstrate the association between HRT and periodontal disease [15-19]. However, the effects of HRT varied according to menopausal age and the postmenopausal period, while also showing conflicting results according to the extent of periodontal disease progression $[15,16]$. In other words,
HRT may have a positive effect on alveolar bone density, but it was reported to have no relationship with the attachment level of periodontal tissues and periodontal pocket depth [17-19]. Although it is believed that HRT applied to postmenopausal women was related to periodontal disease based on its mechanism, existing studies regarding the relationship between HRT and periodontal disease have produced inconsistent results. Accordingly, the objective of the present study was to identify the relationship between HRT and the risk of periodontal disease in postmenopausal women by using data from the Korea National Health and Nutrition Examination Survey (KNHANES) IV and V. The study aimed to analyze the association between HRT and the risk of periodontal diseases in menopausal women to provide basic data that can be used to establish oral health policies for menopausal women according to their life stages. For this, the study aimed to increase internal validity by using propensity score matching (PSM) to adjust for confounding factors and selection bias attributable to observational studies.

\section{Methods}

\section{Study data and study population}

The present study used data from the fourth (20072009) and fifth $(2010,2012)$ KNHANES conducted by the Korea Centers for Disease Control and Prevention, with exemption from review (HYI-16-195) by the Institutional Review Board (IRB) at Hanyang University. KNHANES data were collected using stratified, clustered, and systematic sampling [20]. The sampling method was adjusted for the number of households while accounting for region, type of residence, and administration district in the Republic of Korea [21]. KCDC has published the Korea Health Statistics each year, and microdata are publicly available through the KNHANES website (http://knhanes.cdc.go.kr). Based on the data from subjects who completed their health questionnaire survey and health examination, the study population was limited to menopausal women who were defined as having 12 months of consecutive amenorrhea without apparent cause, such as pregnancy or lactation [22]. Cases involving artificial menopause due to surgeries or diseases were excluded. Moreover, based on the criteria for normal menopausal age given by the Korean Society of Menopause, only women between the ages of 45 and 74 years old were included. Among the total of 5,482 women selected by the method above, a total of 2,070 women (1,035 in the HRT group and 1,035 in the non-HRT group, based on matching results) were selected for the final analysis.

\section{Questionnaire survey}

As the dependent variable, the community periodontal index of treatment needs (CPITN) that has a score range 
of $0-4$ points was reclassified as "No" $(0-2)$ and "Yes" (3-4) to periodontal disease. CPITN is an index that demonstrates the need for periodontal treatment in a specific cohort or entire population of a local community, providing guidelines for understanding the status of periodontal health in a local community, establishing a periodontal treatment plan, and ensuring effective usage of periodontal treatment resources [23]. For the independent variable, the use of female HRT for at least one month was reclassified as HRT+/HRT-. The study also categorized and used the following confounding variables: general characteristics, such as age $(45-54,55-64$, 65-74 years old), education (elementary and below, middle, high and above), family income (low, middle-low, middle-upper, upper), body mass index (normal, obese) and age of menopause $(<45, \geq 45$ years old); lifestyle habits, such as alcohol (non-drinker, past drinker, current drinker) and smoking (non-smoker, smoker); and oral care status, such dental clinic visits in the past year (yes, no), use of oral care products (yes, no), and frequency of tooth brushing per day $(<3, \geq 3$ times).

\section{Statistical analysis}

When analyzing the association between HRT and periodontal disease, propensity score matching (PSM) was used for balancing by controlling the covariates. Propensity score matching is a method that equates treatment and control groups on a comprehensive set of measured confounders in observational studies [24]. PSM is a single numerical value of probability that summarizes the selected confounder, using logistic regression analysis. For this analysis, HRT was the dependent variable, while education level, family income level, and age of menopause were used as covariates. Based on the propensity scores estimated in this manner, HRT+ and HRTgroups were matched 1:1 by the nearest matching neighbor. Before matching, the study population included a total of 5,482 women (4,447 in the HRT- and 1,035 in the HRT+ groups). After PSM, a total of 2,070 women were included (1,035 in the HRT+ and 1,035 in the HRT- groups) (Fig. 1).

To verify that matching was successful, differences between the confounding variables based on HRT+/HRTwere tested by the chi-square test. Moreover, binary logistic regression analysis was performed to identify the factors associated with HRT and periodontal disease, and from these results, the adjusted odds ratio (Adjusted OR) and 95\% confidence interval (CI) were presented. The statistical significance level was set to $p<0.05$. Analysis was also performed with inclusion of interaction variables to examine the interaction effects between HRT and age of menopause. STATA 11.0 (StataCorp LP, TX, USA) was used for all analyses.

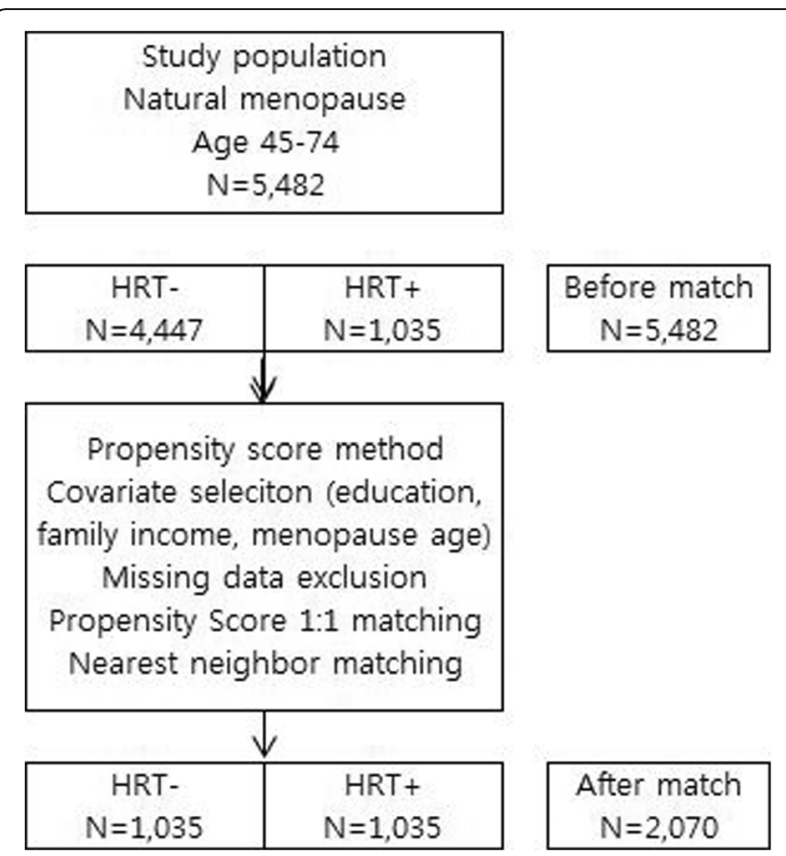

Fig. 1 Flow chart of study population.

\section{Results}

Analysis of differences before and after propensity score matching

After matching for education level, household income, and age of menopause, based on the analysis of differences before and after PSM of all study populations, prematching differences in covariates according to HRT + / HRT- are shown on the left side and post-matching differences are shown on the right side. Before matching, the total study population included 5,482 women; 4,447 in the HRT- group with no experience of HRT and 1,035 in the HRT+ group with previous experience with HRT. After matching, the study population was narrowed to 2,070 women, with 1,035 each in HRT- and HRT+ groups. Before matching, there was a significant difference in HRT status based on education, family income, periodontal disease, age, body mass index, drinking, dental clinic visits in the past 1 year, use of oral care products, and frequency of tooth brushing per day. After matching, there was a significant difference in HRT status based on periodontal disease, age, drinking, and use oral care products. Variables that exhibited differences based on $\mathrm{HRT}+/-$ prior to matching - including education level, household income, and age of menopause - no longer showed differences based on HRT $+/-$ after matching, suggesting that PSM has been successfully completed (Table 1).

\section{Comparison of existence of periodontal diseases according to the general characteristics of the subjects} The association between the general characteristics of the subjects and periodontal diseases after PSM showed 
Table 1 Analysis of differences before and after propensity score matching

\begin{tabular}{|c|c|c|c|c|c|c|c|c|c|c|c|}
\hline \multirow{3}{*}{$\begin{array}{l}\text { Characteristics } \\
\text { Education }\end{array}$} & \multirow{3}{*}{$\begin{array}{l}\text { Group } \\
\text { Elementary and below }\end{array}$} & \multicolumn{5}{|c|}{ Before matching $(5,482)$} & \multicolumn{5}{|c|}{ After matching $(2,070)$} \\
\hline & & \multicolumn{2}{|c|}{ HRT- $(4,447)$} & \multicolumn{2}{|c|}{$\mathrm{HRT}+(1,035)$} & \multirow{2}{*}{$\begin{array}{l}\times 2 \\
<0.001^{* * *}\end{array}$} & \multicolumn{2}{|c|}{ HRT- $(1,035)$} & \multicolumn{2}{|c|}{ HRT+ $(1,035)$} & \multirow{2}{*}{$\frac{\times 2}{1.000}$} \\
\hline & & 2,785 & $(62.63)$ & 460 & $(44.44)$ & & 460 & $(44.44)$ & 460 & $(44.44)$ & \\
\hline & Middle & 693 & (15.58) & 218 & $(21.06)$ & & 218 & $(21.06)$ & 218 & $(21.06)$ & \\
\hline & High and above & 969 & $(21.79)$ & 357 & (34.49) & & 357 & $(34.49)$ & 357 & $(34.49)$ & \\
\hline \multirow[t]{4}{*}{ Family income ${ }^{a}$} & Low & 1,543 & $(34.70)$ & 214 & $(20.68)$ & $<0.001^{* * *}$ & 214 & $(20.68)$ & 214 & $(20.68)$ & 1.000 \\
\hline & Middle low & 1,228 & $(27.61)$ & 289 & $(27.92)$ & & 289 & $(27.92)$ & 289 & $(27.92)$ & \\
\hline & Middle upper & 867 & (19.50) & 251 & $(24.25)$ & & 251 & $(24.25)$ & 251 & $(24.25)$ & \\
\hline & Upper & 809 & (18.19) & 281 & $(27.15)$ & & 281 & $(27.15)$ & 281 & $(27.15)$ & \\
\hline \multirow[t]{2}{*}{ Age of menopause(y) } & $<45$ & 637 & $(14.32)$ & 163 & $(15.75)$ & 0.242 & 163 & $(15.75)$ & 163 & $(15.75)$ & 1.000 \\
\hline & $\geq 45$ & 3,810 & (85.68) & 872 & $(84.25)$ & & 872 & $(84.25)$ & 872 & $(84.25)$ & \\
\hline \multirow[t]{2}{*}{ Periodontal disease } & No & 2,657 & $(59.75)$ & 686 & $(66.28)$ & $<0.001^{* * *}$ & 629 & $(60.77)$ & 686 & $(66.28)$ & $0.009^{* *}$ \\
\hline & Yes & 1,790 & $(40.25)$ & 349 & (33.72) & & 406 & (39.23) & 349 & $(33.72)$ & \\
\hline \multirow[t]{3}{*}{ Age (y) } & $45-54$ & 990 & $(22.26)$ & 265 & $(25.60)$ & $<0.001^{* * *}$ & 331 & (31.98) & 265 & $(25.60)$ & $<0.001^{* * *}$ \\
\hline & $55-64$ & 1,726 & $(38.81)$ & 516 & $(49.86)$ & & 394 & $(38.07)$ & 516 & $(49.86)$ & \\
\hline & $65-74$ & 1,731 & (38.93) & 254 & $(24.54)$ & & 310 & $(29.95)$ & 254 & $(24.54)$ & \\
\hline \multirow[t]{2}{*}{ Body mass index ${ }^{b}$} & Normal & 2,662 & $(59.86)$ & 655 & (63.29) & $0.042^{*}$ & 654 & (63.19) & 655 & $(63.29)$ & 0.964 \\
\hline & Obese & 1,785 & $(40.14)$ & 380 & $(36.71)$ & & 381 & $(36.81)$ & 380 & $(36.71)$ & \\
\hline \multirow[t]{3}{*}{ Alcohol } & No & 1,459 & $(32.81)$ & 266 & $(25.70)$ & $<0.001^{* * *}$ & 321 & $(31.01)$ & 266 & $(25.70)$ & $0.019^{*}$ \\
\hline & Past & 1,868 & $(42.01)$ & 449 & (43.38) & & 432 & $(41.74)$ & 449 & $(43.38)$ & \\
\hline & Drinking & 1,120 & $(25.19)$ & 320 & $(30.92)$ & & 282 & $(27.25)$ & 320 & $(30.92)$ & \\
\hline \multirow[t]{2}{*}{ Smoking } & No & 4,127 & $(92.80)$ & 963 & (93.04) & 0.788 & 961 & $(92.85)$ & 963 & $(93.04)$ & 0.864 \\
\hline & Yes & 320 & $(07.20)$ & 72 & $(06.96)$ & & 74 & $(07.15)$ & 72 & $(06.96)$ & \\
\hline \multirow[t]{2}{*}{ Dental visit $<1$ years } & No & 3,531 & $(79.40)$ & 741 & (71.59) & $<0.001^{* * *}$ & 760 & $(73.43)$ & 741 & $(71.59)$ & 0.351 \\
\hline & Yes & 916 & $(20.60)$ & 294 & $(28.41)$ & & 275 & $(26.57)$ & 294 & $(28.41)$ & \\
\hline \multirow[t]{2}{*}{ Use of oral care products } & No & 3,337 & (75.04) & 627 & $(60.58)$ & $<0.001^{* * *}$ & 685 & $(66.18)$ & 627 & $(60.58)$ & $0.008^{* *}$ \\
\hline & Yes & 1,110 & $(24.96)$ & 408 & $(39.42)$ & & 350 & $(33.82)$ & 408 & $(39.42)$ & \\
\hline \multirow[t]{2}{*}{ Frequency of tooth brushing per day } & $<3$ & 2,852 & (64.13) & 608 & $(58.74)$ & $0.001^{* *}$ & 581 & $(56.14)$ & 608 & $(58.74)$ & 0.231 \\
\hline & $\geq 3$ & 1,595 & $(35.87)$ & 427 & $(41.26)$ & & 454 & $(43.86)$ & 427 & $(41.26)$ & \\
\hline
\end{tabular}

HRT hormone replacement therapy

${ }^{a}$ Income quartile. ${ }^{b}$ Asia-Pacific Standard: normal, less than $25 \mathrm{~kg} / \mathrm{m}^{2}$; obese, more than $25 \mathrm{~kg} / \mathrm{m}^{2}$

${ }^{*} p<0.05,{ }^{* *} p<0.01,{ }^{* * *} p<0.001$

statistically significant differences based on HRT status, education, family income, smoking, use of oral care products, and frequency of tooth brushing per day. The HRT- group(39.23\%) showed a higher prevalence of periodontal disease than the HRT+ group(33.72\%). Moreover, the prevalence of periodontal diseases was higher in those with a lower education level and household income, as well as those who were smokers, did not use oral care products, and brushed their teeth $<3$ times a day (Table 2).

\section{Factors associated with periodontal status}

The binary logistic regression analysis regarding factors associated with the general characteristics of the subjects, periodontal disease, and HRT status after Propensity score matching showed that the HRT+ group had an adjusted OR of 0.79 (95\% CI: 0.66-0.94) for those with periodontal disease, as compared to the HRTgroup. The analysis including the interaction variables for interaction effects between HRT status and age of menopause after adjusting for all other factors showed that the premature menopause HRT+ group had an adjusted OR of 0.55 (95\% CI: $0.35-0.87)$ for those with periodontal disease, as compared to the premature menopause HRT- group, while the adjusted OR for those with periodontal disease was 0.71 (95\% CI: $0.50-1.00)$ and 0.60 (95\% CI: $0.42-0.85)$ in the normal menopause HRT- and HRT+ groups, respectively. The upper household income group had an adjusted OR of 0.74 (95\% CI: 0.55-0.99) for those with periodontal disease, as compared to the low household income group. Meanwhile, the adjusted OR for those with periodontal disease in 
Table 2 General characteristics of the subjects and periodontal disease after propensity score matching $(n=2,070)$

\begin{tabular}{|c|c|c|c|c|c|c|}
\hline \multirow{3}{*}{$\begin{array}{l}\text { Characteristics } \\
\text { HRT status }\end{array}$} & \multirow{3}{*}{$\begin{array}{l}\text { Group } \\
\text { HRT- }\end{array}$} & \multicolumn{4}{|c|}{ Periodontal disease } & \multirow{3}{*}{$\begin{array}{l}x^{2} \\
0.009^{* *}\end{array}$} \\
\hline & & \multicolumn{2}{|c|}{ No $(N=1,315)$} & \multicolumn{2}{|c|}{ Yes $(N=755)$} & \\
\hline & & 629 & $(60.77)$ & 406 & $(39.23)$ & \\
\hline & HRT+ & 686 & $(66.28)$ & 349 & $(33.72)$ & \\
\hline \multirow[t]{3}{*}{ Age(y) } & $45-54$ & 395 & $(66.28)$ & 201 & $(33.72)$ & 0.089 \\
\hline & $55-64$ & 581 & $(63.85)$ & 329 & $(36.15)$ & \\
\hline & $65-74$ & 339 & $(60.11)$ & 225 & (39.89) & \\
\hline \multirow[t]{3}{*}{ Education } & Elementary and below & 542 & $(58.91)$ & 378 & $(41.09)$ & $<0.001^{* * *}$ \\
\hline & Middle & 287 & $(65.83)$ & 149 & $(34.17)$ & \\
\hline & High and above & 486 & $(68.07)$ & 228 & (31.93) & \\
\hline \multirow[t]{4}{*}{ Family income ${ }^{a}$} & Low & 255 & $(59.58)$ & 173 & $(40.42)$ & $<0.001^{* * *}$ \\
\hline & Middle low & 350 & $(60.56)$ & 228 & $(39.45)$ & \\
\hline & Middle upper & 309 & $(61.55)$ & 193 & $(38.45)$ & \\
\hline & Upper & 401 & $(71.35)$ & 161 & $(28.65)$ & \\
\hline \multirow[t]{2}{*}{ Body mass index ${ }^{b}$} & Normal & 850 & $(64.94)$ & 459 & $(35.06)$ & 0.081 \\
\hline & Obese & 465 & $(61.11)$ & 296 & $(38.9)$ & \\
\hline \multirow[t]{2}{*}{ Age of menopause(y) } & $<45$ & 197 & $(60.43)$ & 129 & $(39.57)$ & 0.206 \\
\hline & $\geq 45$ & 1118 & $(64.11)$ & 626 & $(35.89)$ & \\
\hline \multirow[t]{3}{*}{ Alcohol consumption } & No & 364 & $(62.01)$ & 223 & (37.99) & 0.662 \\
\hline & Past & 566 & $(64.24)$ & 315 & $(35.75)$ & \\
\hline & Drinking & 385 & $(63.95)$ & 217 & $(36.05)$ & \\
\hline \multirow[t]{2}{*}{ Smoking } & No & 1247 & $(64.81)$ & 677 & (35.19) & $<0.001^{* * *}$ \\
\hline & Yes & 68 & $(46.58)$ & 78 & $(53.42)$ & \\
\hline \multirow[t]{2}{*}{ Dental visit $<1$ years } & No & 953 & $(63.49)$ & 548 & $(36.51)$ & 0.956 \\
\hline & Yes & 362 & $(63.62)$ & 207 & (36.38) & \\
\hline \multirow[t]{2}{*}{ Use of oral care products } & No & 791 & $(60.29)$ & 521 & (39.71) & $<0.001^{* * *}$ \\
\hline & Yes & 524 & $(69.13)$ & 234 & $(30.87)$ & \\
\hline \multirow[t]{2}{*}{ Frequency of tooth brushing per day } & $<3$ & 726 & $(61.06)$ & 463 & $(38.94)$ & $0.007^{* *}$ \\
\hline & $\geq 3$ & 589 & $(66.86)$ & 292 & (33.14) & \\
\hline
\end{tabular}

HRT hormone replacement therapy

${ }^{a}$ Income quartile. ${ }^{b}$ Asia-Pacific Standard: normal, less than $25 \mathrm{~kg} / \mathrm{m}^{2}$; obese, more than $25 \mathrm{~kg} / \mathrm{m}^{2}$

${ }^{* *} p<0.01,{ }^{* * *} p<0.001$

those who responded "Yes" to smoking and the use of oral care products was 2.04 (95\% CI: $1.44-2.89)$ and 0.78 (95\% CI: 0.63-0.95), respectively (Table 3).

\section{Discussion}

After adjusting for various potential factors associated with periodontal diseases, the study found that HRT and periodontal diseases were associated. The analysis of menopausal women aged between 45 and 74 years old showed that the HRT+ group was less likely to develop periodontal diseases than the HRT- group, which supported the results of previous studies. In a case-control study by Haas et al. that examined Brazilian women aged 40 69 years old, the likelihood of periodontal diseases in the group who did not undergo HRT during menopause was 2.10 times higher than the pre-menopausal women; while, the likelihood of the group who underwent HRT during menopause was 1.11 times higher than the premenopausal women. These results show a similar context to the present study and HRT may be viewed as an option for lowering the risk of exacerbating periodontal status. However, a study by Pizzo et al. evaluating 91 Italian menopausal women aged 50 62 years reported that there was no difference in periodontal pocket depth between the group who underwent HRT and the group who did not, but the group who did not undergo HRT had a higher plaque level. A case-control study by López-Marcos et al. [25] on 210 Spanish menopausal women aged 40-58 years reported that the estrogen patch group showed a reduction in periodontal pocket depth, but since an association with receding gums could not be found, further consideration was needed on 
Table 3 Association between HRT and periodontal disease $(n=2,070)$

\begin{tabular}{|c|c|c|c|}
\hline Variable & & Adjusted OR & $(95 \% \mathrm{Cl})$ \\
\hline \multirow[t]{2}{*}{$\overline{\mathrm{HRT}}$} & HRT- & 1.000 & \\
\hline & HRT+ & $0.79^{* *}$ & $0.66-0.94$ \\
\hline \multirow{5}{*}{$\begin{array}{l}\text { Age_menopause } \\
\text { \#HRT_status }\end{array}$} & $<45 \#$ HRT- & 1.000 & \\
\hline & $<45 \# \mathrm{HRT}+$ & $0.55^{*}$ & $0.35-0.87$ \\
\hline & $\geq 45 \# \mathrm{HRT}$ - & $0.71^{*}$ & $0.50-1.00$ \\
\hline & $\geq 45 \# \mathrm{HRT}+$ & $0.60^{* *}$ & $0.42-0.85$ \\
\hline & $45-54$ & 1.000 & \\
\hline \multirow[t]{2}{*}{ Age } & $55-64$ & 1.09 & $0.86-1.38$ \\
\hline & $65-74$ & 1.08 & $0.82-1.42$ \\
\hline \multirow[t]{3}{*}{ Education } & Elementary and below & 1.000 & \\
\hline & Middle & 0.85 & $0.66-1.09$ \\
\hline & High and above & 0.85 & $0.67-1.08$ \\
\hline \multirow[t]{4}{*}{ Family income } & Low & 1.000 & \\
\hline & Middle low & 1.05 & $0.81-1.37$ \\
\hline & Middle upper & 1.08 & $0.82-1.44$ \\
\hline & Upper & $0.74^{*}$ & $0.55-0.99$ \\
\hline \multirow[t]{2}{*}{ Bmi } & Normal & 1.000 & \\
\hline & Over & 1.09 & $0.90-1.32$ \\
\hline \multirow[t]{3}{*}{ Alchol } & No & 1.000 & \\
\hline & Past & 0.93 & $0.75-1.16$ \\
\hline & Dringking & 0.93 & $0.73-1.20$ \\
\hline \multirow[t]{2}{*}{ Smoking } & No & 1.000 & \\
\hline & Yes & $2.04^{* * *}$ & $1.44-2.89$ \\
\hline \multirow[t]{2}{*}{ Dental visit $<1$ years } & No & 1.000 & \\
\hline & Yes & 1.12 & $0.91-1.38$ \\
\hline \multirow{2}{*}{$\begin{array}{l}\text { Use of secondary oral } \\
\text { products }\end{array}$} & No & 1.000 & \\
\hline & Yes & $0.78^{*}$ & $0.63-0.95$ \\
\hline \multirow{2}{*}{$\begin{array}{l}\text { Frequency of tooth } \\
\text { brushing per day }\end{array}$} & $<3$ & 1.000 & \\
\hline & $\geq 3$ & 0.85 & $0.70-1.02$ \\
\hline
\end{tabular}

HRT hormone replacement therapy

${ }^{a}$ Income quartile b Asia-Pacific Standard: normal, less than $25 \mathrm{~kg} / \mathrm{m}^{2}$; obese, more than $25 \mathrm{~kg} / \mathrm{m}^{2}$

${ }^{*} p<0.05,{ }^{* *} p<0.01,{ }^{* * *} p<0.001$

this topic. These conflicting study results may exist because of varying clinical assessment tools for age group, menopausal period, and periodontal status.

According to precedent studies, subjects in the same age group showed differences in the effects of HRT depending on the menopausal period. Singh et al. [26], Richa et al. [27] reported that the effects of estrogen were greater in people with a longer menopausal period and lower bone mass. Meanwhile, women with premature menopause occurring before the average menopausal age of 50 were reported to have a higher risk of osteoporosis, cardiovascular disease, and associated mortality rate than women with normal menopause due to having a longer period of estrogen deficiency [28]. A prospective study by Women's Health Initiative (WHI) compared BMD after dividing the subjects into groups of menopausal age of $<40$ and $\geq 40$ years. The results showed that the $<40$-year-old group had a statistically significantly lower BMD and the risk of fracture was also higher in the premature menopause group [29]. Sullivan et al. [30] reported that among women who did not undergo HRT, those who experienced menopause at an earlier age tended to have a high risk of fracture and reduction in BMD, while Faubion et al. [31] reported that women with early estrogen deficiency had the need for estrogen therapy with a higher dose due to increased risk of reduction in BMD and death than normal menopausal women.

In the present study, the effects of HRT were more evident in women with premature menopause, before the age of 45 years, which supported the findings in existing studies. This occurs because the effects of HRT are more prominent in premature menopausal women because they have a lower BMD for a longer period of estrogen deficiency, which was consistent with a 3-year prospective study by PEPI, in which the patient age and pre-treatment BMD were the factors associated with an increase in post-HRT BMD [32].

In the present study, In this study, the 'upper' household income group exhibited lower prevalence of periodontal disease, while smokers and users of oral hygiene products exhibited higher prevalence of periodontal disease. Such results were similar to the findings in studies by Schuch et al. [33] where people with a higher education level and income tended to have a higher rate of undergoing treatment for periodontal disease.

MacFarlane et al. [34] have reported that patients with chronic periodontal disease showed impaired phagocytic function compared to those who managed the average adhesion an ingestion of polymorphonuclear leukocytes. Reduction in BMD caused by smoking is especially evident in menopausal women [35]. These results are connected to the effects of HRT appearing more prominently when the periodontal status is poorer. Based on the aforementioned results, it is determined that for premature menopause, HRT should be seriously considered due to an increased risk of bone loss and periodontal disease caused by prolonged estrogen deficiency. Moreover, HRT may be more effective in premature menopausal women with a poor periodontal status.

The present study aimed to be highly representative of Korea by using the KNHANES data that measured the periodontal status according to WHO criteria. However, because it was a cross-sectional study, there were limitations because causal relationships between the influencing factors and the onset of periodontal disease could not be identified and the duration of HRT was not considered. Compared to existing studies, the significance of 
the present study can be found in that it used CPITN, an objective periodontal status assessment tool, and that various factors such as age, age at menopause, and oral care behavior were adjusted to analyze the association between HRT and periodontal disease with consideration for a more diverse set of factors.

\section{Conclusions}

The present study was performed to identify the association between HRT and periodontal disease in menopausal women in Korea by using the data from the KNHANES IV and V. The study used CPITN as an objective assessment tool for periodontal status and adjusted for various factors, such as age, menopausal age, and oral care behavior to more definitively identify the association between HRT and periodontal disease. The results showed that HRT was associated with a lower risk of periodontal disease. Such effect was more evident in women who experienced premature menopause, did not maintain proper oral care, had a lower income level, and were smokers. Therefore, when establishing oral health policies for menopausal women, serious consideration should be given to HRT. Moreover, healthcare programs involving HRT, regular dental check-ups, and oral care need to be implemented especially for premature menopausal women who are smokers.

\section{Abbreviations}

CPITN: Community periodontal index of treatment needs; HRT: Hormone replacement therapy; KNHANES: Korea national health and nutrition examination survey; PSM: Propensity score matching

\section{Acknowledgements}

Not applicable.

\section{Authors' contributions}

YHL and IAK conducted the study and revised the final manuscript. JCS made substantial contributions to conception and design, retrieved the data and wrote the manuscript. KKH and SSH made designed the study, and performed the statistical analysis. BYC had been involved in revising it critically for important intellectual content. All authors read and approved the final manuscript.

\section{Funding}

Not applicable.

\section{Availability of data and materials}

The dataset used and/or analyzed during the current study available from the corresponding author on reasonable request.

\section{Ethics approval and consent to participate}

This study used data from the fourth (2007-2009) and fifth $(2010,2012)$ KNHANES conducted by the Korea Centers for Disease Control and Prevention, with exemption from review (HYI-16-195) by the Institutional Review Board (IRB) at Hanyang University.

\section{Consent for publication}

Not applicable.

\section{Competing interests}

The authors declare that they have no competing interests.

\section{Author details}

'Department of Dental Hygiene, Seoyeong University, 170, Seoyeong-ro, Wollong-myeon, Paju-si, Gyeonggi-do, Republic of Korea. ${ }^{2}$ Department of Occupational and Environment Medicine, College of Medicine, Hanyang University, 222 wangsimni-ro, Seongdong-gu, Seoul, Republic of Korea. ${ }^{3}$ Department of Dentistry/Oral and Maxillofacial Surgery, College of Medicine, Hanyang University, 222 wangsimni-ro, Seongdong-gu, Seoul, Republic of Korea. ${ }^{4}$ Department of Preventive Medicine, College of Medicine, Hanyang University, 222 wangsimni-ro, Seongdong-gu, Seoul, Republic of Korea. ${ }^{5}$ Department of Public Health Sciences, Graduate School of Public Health, Seoul National University, 1, Gwanak-ro, Gwanak-gu, Seoul, Republic of Korea.

Received: 26 July 2018 Accepted: 1 July 2019

Published online: 15 July 2019

\section{References}

1. WHO Scientific Group. Research on the menopause in the 1990s. World Health Organ Tech Rep Ser. 1996;866:1-107.

2. Gold EB. The timing of the age at which natural menopause occurs. Obstet Gynecol Clin N Am. 2011;38(3):425-40.

3. Korean Statistical Information Service: A life table in 2015. 2017 http://kostat.go.kr/wnsearch/search.jsp. Accessed 3 Oct 2017.

4. Lim K. The study of menopause-related quality of life and management of climacteric in a middle-aged female population in Korea. PHWR. 2013;6(31): 609-13

5. Poomalar GK, Arounassalame B. The quality of life during and after menopause among rural women. J Clin Diagnostic Res. 2013;7(1):135-9.

6. Levin VA, Jiang $X$, Kagan R. Estrogen therapy for osteoporosis in the modern era. Osteoporos Int. 2018;29(5):1049-55.

7. Megson E, Kapellas K, Bartold PM. Relationship between periodontal disease and osteoporosis. Int J Evid Based Healthc. 2010;8(3):129-39.

8. Hernández-Vigueras S, Martínez-Garriga B, Sánchez MC, Sanz M, EstrugoDevesa A, Vinuesa T, et al. Oral microbiota, periodontal status, and osteoporosis in postmenopausal females. J Periodontol. 2016;87(2):124-33.

9. Shu L, Guan S-M, Fu S-M, Guo T, Cao M, Ding Y. Estrogen modulates cytokine expression in human periodontal ligament cells. J Dent Res. 2008; 87(2):142-7.

10. Suri V, Suri V. Menopause and oral health. J Midlife Health. 2014;5(3):115-20.

11. The NAMS 2017 Hormone Therapy Position Statement Advisory Panel. The 2017 hormone therapy position statement of the North American Menopause Society. Menopause. 2017;24(7):728-53.

12. Levin VA, Jiang $X$, Kagan R. Estrogen therapy for osteoporosis in the modern era. Osteoporos Int. 2018; 29(5):1049-55.

13. Civitelli R, Pilgram TK, Dotson M, Muckerman J, Lewandowski N, Armamento-Villareal $\mathrm{R}$, et al. Alveolar and postcranial bone density in postmenopausal women receiving hormone/estrogen replacement therapy: a randomized, double-blind, placebo-controlled trial. Arch Intern Med. 2002; 162(12):1409-15.

14. Beshay SM, Rivera G, Balthasar J, Florea N. Efficacy and clinical value of commonly compounded hormone replacement therapy: a literature review. Int J Pharm Compd. 2015;19(1):6-12.

15. De Villiers TJ, Gass ML, Haines CJ, Hall JE, Lobo RA, Pierroz DD, et al. Global consensus statement on menopausal hormone therapy. Climacteric. 2013; 16(2):203-4.

16. Zhao H, Li C, Lin L, Pan Y, Wang H, Zhao J, et al. Assessment of alveolar bone status in middle aged Chinese (40-59 years) with chronic periodontitis - using CBCT. PLOS One. 2015. https://doi.org/10.1371/journal.pone.0139553.

17. Haas AN, Rösing CK, Oppermann RV, Albandar JM, Susin C. Association among menopause, hormone replacement therapy, and periodontal attachment loss in southern Brazilian women. J Periodontol. 2009;80(9): 1380-7.

18. Pizzo G, Guiglia R, Licata ME, Pizzo I, Davis JM, Giuliana G. Effect of hormone replacement therapy (HRT) on periodontal status of postmenopausal women. Med Sci Monit. 2011;17(4):PH23-7.

19. Alves RC, Félix SA, Rodriguez-Archilla A, Oliveira P, Brito J, Dos Santos JM. Relationship between menopause and periodontal disease: a cross-sectional study in a Portuguese population. Int J Clin Exp Med. 2015;8(7):11412-9.

20. Kweon S, Kim Y, Jang MJ, Kim Y, Kim K, Choi S, et al. Data resource profile: the Korea National Health and nutrition examination survey (KNHANES). Int J Epidemiol. 2014;43(1):69-77. 
21. Yoon KC, Choi W, Lee HS, Kim SD, Kim SH, Kim CY, et al. An overview of ophthalmologic survey methodology in the 2008-2015 Korean National Health and nutrition examination surveys. Korean J Ophthalmol. 2015;29(6): 359-67.

22. Takahashi TA, Johnson KM. Menopause. Med Clin North Am. 2015;99(3):521-34.

23. Nomura Y, Okada A, Kakuta E, Gunji T, Kajiura S, Hanada N. A new screening method for periodontitis: an alternative to the community periodontal index. BMC Oral Health. 2016;16(1):64.

24. Jupiter DC. Propensity score matching: retrospective randomization? J Foot Ankle Surg. 2017;56(2):417-20.

25. López-Marcos JF, García-Valle S, García-Iglesias AA. Periodontal aspects in menopausal women undergoing hormone replacement therapy. Med Oral Patol Oral Cir Bucal. 2005;10(2):132-41

26. Singh A, Sharma RK, Siwach RC, Tewari S, Narula SC. Association of bone mineral density with periodontal status in postmenopausal women. J Investig Clin Dent. 2014;5(4):275-82.

27. Richa RY, Puranik MP, Shrivastava A. Association between osteoporosis and periodontal disease among postmenopausal Indian women. J Investig Clin Dent. 2017;8(3).

28. Joakimsen O, Bønaa KH, Stensland-Bugge E, Jacobsen BK. Population-based study of age at menopause and ultrasound assessed carotid atherosclerosis - The Tromso Study. J Clin Epidemiol. 2000:53(5):525-30.

29. Sullivan SD, Lehman A, Nathan NK, Thomson CA, Howard BV. Age of menopause and fracture risk in postmenopausal women randomized to calcium + vitamin D, hormone therapy, or the combination: results from the Women's Health Initiative clinical trials. Menopause. 2017;24(4):371-8.

30. Sullivan SD, Sarrel PM, Nelson LM. Hormone replacement therapy in young women with primary ovarian insufficiency and early menopause. Fertil Steril. 2016;106(7):1588-99.

31. Faubion SS, Kuhle CL, Shuster LT, Rocca WA. Long-term health consequences of premature or early menopause and considerations for management. Climacteric. 2015;18(4):483-91.

32. Barrett-Connor E, Espeland MA, Greendale GA, Trabal J, Johnson S, Legault C, et al. Postmenopausal hormone use following a 3-year randomized clinical trial. J Womens Health Gend Based Med. 2000;9(6):633-43.

33. Schuch HS, Peres KG, Singh A, Peres MA, Do LG. Socioeconomic position during life and periodontitis in adulthood: a systematic review. Community Dent Oral Epidemiol. 2017;45(3):201-8.

34. MacFarlane GD, Herzberg MC, Wolff LF, Hardie NA. Refractory periodontitis associated with abnormal polymorphonuclear leukocyte phagocytosis and cigarette smoking. J Periodontol. 1992;63(11):908-13.

35. Ugurlu U, Nayki U, Nayki C, Ulug P, Kulhan M, Yildirim Y. Assessment of smoking for low bone mineral density in postmenopausal Turkish women. Wien Klin Wochenschr. 2016;128(3-4):114-9.

\section{Publisher's Note}

Springer Nature remains neutral with regard to jurisdictional claims in published maps and institutional affiliations.

Ready to submit your research? Choose BMC and benefit from:

- fast, convenient online submission

- thorough peer review by experienced researchers in your field

- rapid publication on acceptance

- support for research data, including large and complex data types

- gold Open Access which fosters wider collaboration and increased citations

- maximum visibility for your research: over $100 \mathrm{M}$ website views per year

At $\mathrm{BMC}$, research is always in progress.

Learn more biomedcentral.com/submissions 